ARS Dalila Camargo Martins*

ano 15

n. 31

\title{
Crônica de Anna Magdalena Bach: amor, trabalho e morte no cinema de Danièle Huillet e Jean-Marie Straub.
}

\section{Chronicle of Anna Magdalena Bach: love, work and death in the cinema} of Danièle Huillet and Jean-Marie Straub.

palavras-chave:

Danièle Huillet e Jean-Marie Straub; novo cinema alemão; autoria

keywords: Danièle Huillet and Jean-Marie Straub; new German cinema; authorship

* Universidade de São Paulo [USP].
Este artigo analisa o filme Crônica de Anna Magdalena Bach (1968), de Danièle Huillet e Jean-Marie Straub, de modo a mostrar como, analogamente, ao tratar de modos de produção artística, desmitifica-se o gênio de Johann Sebastian Bach, contextualizando sua obra na ordem eclesiástica do século XVIII, e se faz uma crítica dos preceitos do Autorenfilm do novo cinema alemão, dependente de um sistema de financiamento estatal, do qual ele faz parte. Ademais, busca-se indicar a possibilidade de formas alternativas de produção artística e percepção sensível engendradas cinematograficamente que se contraponham ao trabalho alienado.

This article analyzes the film Chronicle of Anna Magdalena Bach (1968), by Danièle Huillet and Jean-Marie Straub, in order to show how, analogously, when dealing with modes of artistic production, it demystifies the genius of Johann Sebastian Bach, contextualizing his work in the ecclesiastical order of the 18th century, and it criticizes the precepts of Autorenfilm of the new German cinema, dependent on a system of state funding, in which it takes part of. In addition, it seeks to indicate the possibility of alternative forms of artistic production and sensitive perception engendered cinematographically that are opposed to alienated work. 
Em 1959, após sua deserção do exército francês por se recusar a combater na Guerra da Argélia, Jean-Marie Straub partiu para o exílio na Alemanha, acompanhado de Danièle Huillet, com o projeto de realização do longa-metragem Crônica de Anna Magdalena Bach. O roteiro fora redigido entre 1954 e 1959, a partir do necrológio elaborado por Carl Philipp Emanuel Bach e Johann Friedrich Agricola em 1754, além de cartas, memórias, partituras, mapas, gravuras e outros documentos ou arquivos. Contudo, durante quase uma década, os cineastas depararam com inúmeros percalços para poder filmá-lo tal qual o planejaram, isto é, respeitando a primazia do real - princípio que norteia a integralidade de seu cinema.

Gustav Leonhardt, precursor de práticas autênticas de execução musical em suas interpretações de Bach, trajando indumentária do século XVIII, deveria tocar as peças com instrumentos barrocos nos exatos locais onde eram apresentadas, para a gravação huillet-straubiana em som direto. Pois, "são músicas que ele escreveu para meios muito

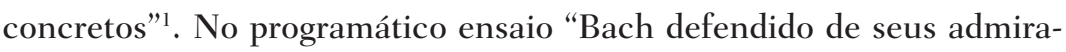
dores", Theodor W. Adorno constatou o perigo do desvirtuamento ideológico dessa busca pela autenticidade:

A obra que se originou dentro dos confinamentos estreitos do horizonte teológico só para rompê-los e ultrapassá-los em direção à universalidade é condenada a voltar aos limites que transcendeu. Bach é degradado pela nostalgia impotente do mesmo compositor eclesiástico contra cujo cargo se rebelou e o qual preencheu em conflito pleno. O que o separou das práticas de sua época, longe de ser compreendido como a contradição de seu conteúdo em relação a elas, torna-se pretexto para glorificar o nimbo da artesania provinciana como qualidade clássica. ${ }^{2}$

Entretanto, Crônica de Anna Magdalena Bach opera de forma antípoda: "aqui eu quero" - diz Straub - "servir-me da realidade para que o aspecto fictício do filme se torne ainda mais evidente, de maneira que no fim tenhamos quase esquecido de que se trata de Bach”3. Em muitas das encenações de seu cotidiano, o compositor é retratado em constante altercação com as autoridades acerca das condições de trabalho. Em 1995, Huillet afirmaria, em entrevista a Jean-Claude Biette e Dominik Loss: "As pessoas" - por meio do filme - "descobriram que Bach tinha superiores e que também compunha música para determi-


ocasiões envolvendo membros da nobreza recebiam peças em dedicatória (como as Variações Goldberg, compostas para amenizar a insônia do conde Hermann Karl von Keyserling) e a elaboração de exercícios solos
174

Dalila Camargo Martins

Crônica de Anna Magdalena

Bach: amor, trabalho e morte no cinema de Danièle Huillet e Jean-Marie Straub.

1. BIETTE, Jean-Claude; LOSS, Dominik. Bach/Schoenberg: entretien avec Jean-Marie Straub et Danièle Huillet. Cahiers du Cinéma, Paris, n. 496, p. 47, nov. 1995. Numéro Spécial: Musique du Cinéma. Tradução minha.

2. ADORNO, Theodor. Defensa de Bach contra sus entusiastas. In: Prismas: la crítica de la cultura y la sociedad. Barcelona: Ariel, 1962, p. 142. Tradução minha.

3. STRAUB, Jean-Marie. O Bachfilm. In: GOUGAIN, Ernesto et al. (orgs.). Straub-Huillet. São Paulo: CCBB, 2012, p. 9.

4. BIETTE; LOSS, Op. cit., p. 47. Tradução minha. 
visava ao aperfeiçoamento musical de seus alunos e membros de sua

ano 15

ก. 31

5. Ibidem, Loc. cit.

6. MANIFESTO OBERHAUSEN apud ELSAESSER, Thomas. New German Cinema: a history. New Brunswick: Rutgers University Press, 1989, p. 20-21. Tradução

minha. família. Bach oferecia, ainda, seus serviços nas trocas de favores com seus patronos. Outro indício fílmico da embrionária amplificação da mercantilização da música é a substituição de partituras manuscritas por folhas impressas. Portanto, o inventário das circunstâncias materiais de produção em que consiste o argumento do filme refuta "a ideia do século XIX (...) de que a arte estava acima de tudo" ${ }^{\text {. }}$.

Além de desmitificar o gênio de Bach, Crônica se reporta ao contexto imediato de sua própria realização, no qual proliferavam mecanismos de subsídios estatais em âmbitos municipais, regionais e federais, com o intuito de fortalecer o mercado cinematográfico na Alemanha Ocidental - desmantelado devido à penetração do excedente hollywoodiano via Motion Picture Export Association e ao monopólio exercido sobre o restante da produção nacional pelas distribuidoras estadunidenses após a derrota na Segunda Grande Guerra. No Manifesto de Oberhausen, marco do novo cinema alemão, publicado em 1962, lê-se:

O colapso da indústria cinematográfica comercial alemã finalmente remove a base econômica para um modo de filmagem cujas atitude e prática nós rejeitamos. Com isto, o novo filme tem a chance de ganhar vida. O sucesso dos curtas alemães em festivais internacionais demonstra que o futuro do cinema alemão repousa com aqueles que têm mostrado falar a linguagem internacional do cinema. Este novo cinema precisa de novas formas de liberdade: em relação às convenções e hábitos da indústria estabelecida, à intervenção de parceiros comerciais, e finalmente liberdade em relação à tutela de outros interesses adquiridos. Nós temos planos específicos para a realização artística, formal e econômica deste novo cinema alemão. Nós estamos coletivamente preparados para assumir riscos econômicos. $\mathrm{O}$ velho cinema está morto. Nós acreditamos no novo. ${ }^{6}$

Apesar das demandas um tanto genéricas, por corresponder a um esforço comum de um grupo heterogêneo com os mais diversos contatos, o manifesto empenhou membros do Bundestag, de comissões especiais e assistentes ministeriais. Seu resultado mais oportuno foi a fundação do Kuratorium, instituição que fomentava a produção de filmes por meio de empréstimos de fundo governamental, cujo pagamento era revertido em novas produções, segundo decisões do comitê de seleção formado majoritariamente por jornalistas especializados. Articulado nos moldes da patronagem tradicionalmente vigente na literatura e nas belas artes, o esquema implicava noção de filme enquanto obra de arte e gesto de autoexpressão, cujo valor estético avultava em detrimento 
da rentabilidade da circulação - pouco dinheiro de fato retornava. Os jovens cineastas deviam defender a autoria de seus projetos perante as bancas avaliadoras e legitimá-la nos festivais internacionais como propaganda do cinema moderno, justificando publicamente suas produções. O aparecimento de escolas técnicas e universidades de cinema para a consolidação de um espectador cinéfilo e intelectualizado completa o quadro desse incentivo à cultura.

A má experiência de Huillet-Straub com esse modelo é bem conhecida. Muitos produtores privados hesitaram em investir em Crônica de Anna Magdalena Bach, com exceção de Franz Seitz e Gian Vittorio Baldi. Entretanto, o caminho estatal se mostrou tão árduo quanto. O projeto foi declinado repetidamente pela FFA (Junta de Subsídio Federal), em Bonn, e pelo Ministério da Cultura, em Düsseldorf. Até mesmo o Kuratorium, suscetível a filmes com selo de originalidade, indeferiu a primeira aplicação, impelindo a constituição de um financiamento coletivo coordenado pela revista Filmkritik. Entre os apoiadores, figuram Alexander Kluge, Volker Schlöndorff, François Truffaut e Enno Patalas. Apenas um mês antes da filmagem, em julho de 1967, o Kuratorium aprovou a quantia de 150 mil marcos, metade do que já empregara em filmes menos impactantes. Quanto à distribuição, o casal de cineastas sondou a televisão bávara, a UFA (Universum Film Aktiengesellschaft) e mesmo a DEFA (Deutsche Film Aktiengesellschaft), emissora da Alemanha Oriental. Apesar do sucesso de crítica alcançado pelo filme em festivais como os de Berlim e Cannes, no verão de 1968, o FBW (Órgão de Classificação de Filmes de Wiesbaden) se negou a classificá-lo como "bom" ou "excelente", o que lhe garantiria a redução nos impostos.

Não obstante tais empecilhos, provavelmente por causa da insistência de Huillet-Straub em uma estética cinematográfica inexorável que pressupunha métodos inusuais de produção, o incômodo provocado pelo projeto de Crônica se estendeu ao truste da indústria fonográfica alemã, cujos magnatas queriam manter nas salas de concerto a música de um ícone nacional consagrado pela burguesia. Em 2001, em entrevista a François Albera, Straub relataria as tentativas de boicote e corrupção:

Fizemos Crônica de Anna Magdalena da maneira que queríamos fazê-lo e não como as pessoas nos aconselharam a fazer durante os dez anos em que esperamos para poder fazê-lo. O primeiro com Curt Jürgens, o segundo usando o dobro de dinheiro que teria custado o filme, mas pagando Herbert von Karajan...

E nós mandamos todos eles se ferrarem, porque queríamos fazer esse filme com Gustav Leonhardt que, na época, não estava entre os sucessos de bilhe-
Dalila Camargo Martins

Crônica de Anna Magdalena

Bach: amor, trabalho e morte no cinema de Danièle Huillet e Jean-Marie Straub. 
ARS

ano 15

ก. 31

7. ALBERA, François. Cinema [e] política "foice e martelo, canhões, canhões, dinamite!". In: GOUGAIN, Ernesto et al. (orgs.). Straub-Huillet. São Paulo: CCBB, 2012, p. 76-77. teria da indústria cultural, quando todo mundo, até os músicos e os musicólogos diziam: "Como? Quem?" e tínhamos que escrever seu nome num pedaço de papel. O mesmo aconteceu com Nikolaus Harnoncourt. Quanto ao pobre Wenzinger, o braço direito de Paul Sacher na Basileia, ele também não era conhecido: estão todos no filme com Leonhardt e como isso não tinha valor algum nas bilheterias da indústria cultural, ninguém queria dar um tostão para o filme. Ora, se fazemos um filme politicamente, quer dizer, organizando aquilo que fazemos, isso quer dizer escolher os atores sem se dirigir a casting ou à bilheteria, sob o pretexto que precisamos fazer isso senão não conseguimos dinheiro, que sem Depardieu o filme não se faz, sem a última bela menina da moda não teremos dinheiro do CNC, o filme não irá a Cannes etc. Senão, não só não fazemos politicamente, como também não fazemos os filmes que queremos fazer. Brecht já dizia em seu prefácio a Kuhle Wampe: "a organização nos custou muito mais trabalho do que die kunstlerische arbeit... o trabalho artístico por si só” e, diz ele, isso vem do fato de que era um filme político. ${ }^{7}$

\section{O desejo por outro modo de produção vislumbrado nessa denún-} cia da indústria cultural se explicita na citação de Karl Marx anexada à publicação do roteiro de Crônica de Anna Magdalena Bach, em 1969:

Suponhamos que tivéssemos produzido como seres humanos. Cada um de nós afirmaria duplamente a si mesmo e a outra pessoa:

1) Na minha produção, eu teria tornado objetiva a minha individualidade, o seu caráter específico e, portanto, não só teria desfrutado ao expressar minha vida individual durante a atividade, mas também, ao ver o objeto, eu teria o prazer individual de saber que a minha personalidade é objetiva, perceptível aos sentidos e, portanto, um poder fora de qualquer dívida.

2) $\mathrm{O}$ seu desfrute ou uso de meu produto me proporcionaria diretamente o prazer de me saber satisfazendo com minha atividade uma necessidade $h u$ mana, isto é, de ter tornado objetivo o ser humano, e de ter, assim, criado um objeto correspondente à necessidade de outro ser humano.

3) Eu teria sido para você o mediador entre você e o gênero humano e, portanto, seria reconhecido e sentido por você como um preenchimento da sua própria natureza essencial e como uma parte necessária de você mesmo e, consequentemente, eu me sentiria confirmado tanto no seu pensamento como no seu amor.

4) Teria tido a alegria de, na expressão individual de minha vida, eu ter criado diretamente a expressão de sua vida, e, portanto, de na minha atividade individual, eu ter diretamente confirmado e realizado o meu verdadeiro ser, o meu ser humano, meu ser em comum [gemeinwesen]. 
Nossas produções seriam múltiplos espelhos em que veríamos refletida a nossa natureza essencial. ${ }^{8}$

Essa utopia de um trabalho não alienado é a contraparte da intenção de Straub de se servir "da realidade para que o aspecto fictício do filme se torne ainda mais evidente, de maneira que no fim tenhamos quase esquecido de que se trata de Bach”. Ou seja, Crônica não apenas desmitifica o gênio do artista, ao exibir o processo musical como trabalho, mas também denota que "não há nele a menor separação entre inteligência, arte e vida, muito menos conflito entre a música 'profana' e a 'sagrada', nele tudo está no mesmo plano"9.

Ao comentar os trechos do filme em que um conjunto se agrupa em torno de Bach conduzindo a performance, em oposição ao plano rijo no qual meninos do internato se sentam à mesa do refeitório perfilados a rezar sob sua supervisão - síntese da hierarquia do metiê -, Straub diz: "Alguma coisa emana deste ponto focal e se produz no sentido em que Brecht define o amor - 'a arte de produzir algo com as capacidades do outro"” ${ }^{10}$. Portanto, Huillet e Straub não somente constroem analogia temática entre seu vínculo e o do compositor com os respectivos aparelhos de patrocínio nos diferentes períodos, como revelam a totalidade produtiva de uma criação que luta para se repor com feitio orgânico no transcorrer das eras - um corpus cuja ubiquidade perdura para além do domínio de um indivíduo isolado.

O filme, cujo título Straub retirou do livro Pequena crônica de Anna Magdalena Bach (1925), de Esther Meynell ${ }^{11}$, retrata um destino "que queima como uma vela" ${ }^{2}$. A voz over feminina, conectada diegeticamente à figura de Anna Magdalena (Christiane Lang) em plongée descentrado com a aparência fugaz de um flash, arremata o aspecto novelístico sui generis explorado nele pelos cineastas. Pois, apesar de seguir cronologia "inteiramente clássica, inteiramente linear"13, a narração comedida se contenta em encadear vestígios de um passado em vez de projetar opiniões subjetivas a partir de rememorações psicologicamente motivadas, tirando vantagem da onisciência póstuma.

Em termos de proporção, as reconstituições de acontecimentos profissionais e domésticos - cuja decupagem se dá de modo pouco mais convencional, porém elíptico, e sem caracterização do envelhecimento das personagens com maquiagem ou adereços - preenchem só onze dos noventa e três minutos de duração e não chegam a elaborar uma trama coesa, com crise e superação catártica. Há "sequências, não cenas, nem episódios (...), mas apenas o que Stockhausen chamaria de "pontos"” 14 , termo concernente à música pontilhista, estilo que abrange

\section{Dalila Camargo Martins}

Crônica de Anna Magdalena

Bach: amor, trabalho e morte

no cinema de Danièle Huillet $\mathrm{e}$

Jean-Marie Straub.

8. TRECHOS dos comentários sobre os elementos de economia política de James Mill, por Karl Marx. (1844).

Humanaesfera, [S.l], $18 \mathrm{fev}$.

2014. Disponível em: <https:// goo.gl/m5wvpt>. Acesso em: 22 nov. 2017.

9. STRAUB. Op. cit., p. 9.

10. BIETTE; LOSS, Op. cit., p. 48. Tradução minha.

11. MEYNELL, Esther.

Pequena crônica de Anna Magdalena Bach. Campinas: Veredas, 2005.

12. STRAUB, Jean-Marie; HUILLET, Danièle. Gespräch mit Danièle Huillet und Jean-Marie Straub. Filmkritik, München, n. 10, p. 690, maio 1968. Tradução minha.

13. STRAUB, Jean-Marie apud BÖSER, Ursula. The art of seeing, the art of listening: the politics of representation in the work of Jean-Marie Straub and Danièle Huillet. Frankfurt: Lang, 2004, p. 38. Tradução minha.

14. STRAUB, Op. cit., p. 5. 
partículas de sons dispersos apartados por curtos intervalos, impedindo

15. SCHADHAUSER, Sebastian et al. Entretien avec Jean- Marie Straub et Danièle Huillet. Cahiers du Cinéma, Paris, n. 223, p. 55, ago. 1970. Tradução minha.

16. STRAUB; HUILLET. Op. cit., p. 690. Tradução minha. estruturações tonais. Ademais, a controvérsia acerca da candidatura ao posto de Kantor (diretor musical) na Igreja de São Tomás, em Leipzig, assumido por Bach com acúmulo de deveres após intercessão régia, ou mesmo as disputas de poder entre reitoria da universidade, conselho municipal e consistório conviriam para a análise da conjuntura política do Eleitorado da Saxônia, não fosse o laconismo de suas alusões.

Ora, em Crônica, tudo ocorre como se a passagem do tempo consumisse a história. A morte se faz sempre presente, porém nunca de forma dramática. Mencionam-se, neutralmente, o rol de falecimentos de vários dos filhos de Bach e o suicídio de um vice-reitor. A consolação de um além-vida é recorrente nas músicas, e até mesmo a remuneração do compositor depende da quantidade de funerais celebrados por ano. A interposição de paisagens naturais sempiternas (mar, copas de árvores, pôr-do-sol), alheias à ingerência humana, salientam, por contraste, o fluxo fatalista. A respeito da matéria de seu cinema, Straub explica:

A condensação do tempo, o cinema consiste justamente nisto; isto é o que eu tento filmar ou surpreender, o puro presente condensado. Que passa e que jamais se renovará.... Digamos que o fato de mostrar a morte ao trabalho deveria dar às pessoas o gosto de viver, porque elas devem se dar conta de que cada momento que passa é o fim, não se pode mais recuperá-lo. Deve haver uma ameaça aqui. ${ }^{15}$

Assim, diante do retesamento da morte, "a coisa mais antinatural do mundo" ${ }^{16}$, o filme instiga o espectador a se engajar na realidade, todavia por meio mais sutil do que no jogo de pistas e expectativas em torno do enredo praticado pelo cinema clássico. A montagem de Crônica é contrapontística, incorpora a polifonia bachiana. Huillet e Straub engendram a alternância entre longos e abertos planos-sequências de execução musical, captados de posições singulares em pronunciados ângulos oblíquos e privilegiando a profundidade de campo, às vezes atrelados a ágeis ou lentos trackings in ou out e sumárias inserções de documentos da época, registrados ora com câmera fixa, ora com movimentos de múltiplas velocidades, pans da esquerda para a direita ou tilts de cima para baixo, ressaltando signos ou fragmentos como em ato de leitura. Há, ainda, elementos que destoam absolutamente, como o plano de Bach conduzindo uma orquestra fora de campo em frente a um back projection (!) da prefeitura de Leipzig.

Tais variações em repetições (nunca arbitrárias, mas adequadas à natureza de materiais e situações) instauram dinâmica que estimula o 
espectador a cogitar a relevância semântica de nuances audiovisuais em momentos demorados, sem atrativos pungentes e que o desviam de seus hábitos de atribuição de significados instantâneos perante uma abundância de informações gráficas, as quais correspondem literalmente ao que se mostra, porém não de modo verbal, direto. Ou seja, persegue-se uma afinação da percepção sensível, a qual consiste em outra faceta do intelecto. Ao circunscrever a estética de Crônica na tradição cinematográfica, aproveitando a ocasião para denegar algumas recepções apressadas da crítica, Straub menciona os primórdios:

É uma piada quando alguém diz que é uma tomada estática, que a câmera não se move, que nada acontece. Há mais acontecendo do que em uma pan, uma perseguição de carros, uma caçada. Cada dedo está se mexendo, e até se sente o ar, e ademais, esta é a essência do cinematógrafo: dizem que quando as pessoas viram Le déjeuner de bébé ou L'arroseur arrosé de Lumière, eles não exclamaram: ó, o bébé se move, ou l'arroseur se move. Elas disseram que as folhas se mexiam nas árvores. O bébé se movendo, elas já haviam visto na lanterna mágica. O novo para elas era precisamente que as folhas se mexiam. As "folhas" no filme de Bach são os dedos e mãos dos músicos e os gestos inacreditáveis de Leonhardt, que não são nada monótonos. ${ }^{17}$

Entretanto, se a impressão do espectador de Crônica não deixa de se assemelhar ao efeito surtido pelas vistas de Lumière, o pensamento audiovisual de Huillet e Straub talvez guarde mais afinidades com a teoria eisensteiniana - nesse caso, ao menos, indubitavelmente. Em 1928, em resposta aos lançamentos pioneiros de filmes falados, Sergei Eisenstein, Vsevolod Pudovkin e Grigori Alexandrov publicaram a Declaração sobre o futuro do cinema sonoro, na qual pleiteavam "um uso polifônico do som em relação à peça de montagem visual” como único modo da incipiente tecnologia proporcionar "uma nova potencialidade no desenvolvimento e aperfeiçoamento da montagem"18, o núcleo duro da arte cinematográfica para os soviéticos. Assim, "o primeiro trabalho experimental com o som deve ter como direção a linha de sua distinta não-sincronização com as imagens visuais", pois "apenas uma investida deste tipo dará a palpabilidade necessária que mais tarde levará a criação de um contraponto orquestral das imagens visuais e sonoras" ${ }^{\prime 19}$.

Ora, aqui parece haver uma discrepância com a preconização huillet-straubiana do som direto. Um ano mais tarde, porém, expandiu-se a ideia: "(...) escrevemos sobre um método de contraponto de imagens visuais e auditivas combinadas. Para dominar este método, deve-se

\section{Dalila Camargo Martins}

Crônica de Anna Magdalena

Bach: amor, trabalho e morte no cinema de Danièle Huillet e Jean-Marie Straub.

17. STRAUB; HUILLET, Op. cit., p. 689-690. Tradução minha.

18. EISENSTEIN, Sergei. A forma do filme. Rio de Janeiro: Zahar, 2002, p. 226.

19. Ibidem, Loc. cit. 
desenvolver em si mesmo um novo sentido: a capacidade de reduzir percepções visuais e auditivas a um 'denominador comum"'20. Ao aferir o

20. Ibidem, p. 31

21. Ibidem, p. 29.

22. Ibidem, Loc. cit.
23. SCHADHAUSER et al. Op. cit., p. 54. Tradução minha. modelo do teatro Kabuki, Eisenstein definiu o "conjunto monístico", no qual "som - movimento - espaço - voz (...) não acompanham (nem mesmo são paralelos) um ao outro, mas funcionam como elementos de igual significância" ${ }^{21}$. Tais concepções formais condizem plenamente com o arranjo de Crônica.

O maior dado fílmico dessa "sensação monística", em que "ouvimos movimento e vemos som"22, é uma panorâmica que se refere a um incidente de Bach (em 1747, junto aos filhos Carl Philipp Emanuel e Wilhelm Friedemann) na ópera estatal de Berlim, evocando sua acurada atenção à acústica. Conforme conta o irmão mais novo, ao adentrar o salão, o compositor notou rapidamente que o arquiteto realizara uma proeza: se alguém chegasse em um canto qualquer e sussurrasse algo bem baixo contra a parede, uma pessoa posicionada diagonalmente do lado oposto poderia escutar com toda clareza, ao passo que em nenhum outro ponto do lugar, nem mesmo no meio, o ruído seria audível. O plano começa com um quadro que pega Leonhardt, desde os ombros, olhando o teto da edificação, depois a câmera sobe e varre a extensão da abóboda da esquerda para a direita, até quase concluir um arco. Na banda sonora, a voz over relata e ao fundo se ouve o Ricercar a 6 vozes, fuga integrante da Oferenda musical ao rei Frederico II da Prússia, em cuja corte de Potsdam trabalhava Carl Philipp. Didaticamente, portanto, Huillet-Straub lembram ser "o som que dá o espaço"23.

Tal entendimento se desdobra para outros segmentos do filme, menos explícitos, contudo catalisadores da imaginação sensória do espectador, como quando Bach lê em voz alta seu memorando sobre uma Wohlbestallte Kirchenmusik (bem regulada música de igreja). Essa sequência se inicia com um plano médio em plongée transversal de Leonhardt sentado em uma escrivaninha, citando o documento. Então, há um corte para um plano próximo de Lang, com feição circunspecta, encostada em um painel de madeira, de costas para uma estante cheia de livros. A citação continua em off com nítida mudança na reverberação da voz, o que gera estranho pulo sonoro, mas indica a espacialidade do aposento e as distâncias dos corpos emissores em relação ao microfone e entre si. Decerto, não se compreende muito bem se o casal está no mesmo local, até a adição de um plano master no qual Anna Magdalena atravessa o quadro da direita para a esquerda, encerrando um semicírculo ao redor de Bach, até encostar a mão em seu ombro. 
Essa pequena confusão, traço estilístico da intimidade em que consiste um dos assuntos do filme, além de induzir o espectador a restaurar o espaço pelo som, aponta para o eclipse do trabalho em equipe de Huillet e Straub. Com raras exceções, os cineastas sempre assinaram juntos. No entanto, foi Straub quem ganhou primeiro o prestígio de autor cinematográfico, talvez devido à divisão de tarefas com a qual se acostumaram: na pré-produção, Huillet procedia como filóloga, arrumando os textos a serem adaptados, e ambos redigiam o roteiro, preparavam atores ou não atores e visitavam as locações para decidir a respeito de tecnicalidades; no set, Straub se encarregava do enquadramento com os fotógrafos e das cenas com atores ou não atores - a típica função do diretor -, enquanto ela se concentrava no som e em incumbências de produção e cenografia; na pós, Huillet montava e Straub se sobressaía com sua personalidade contumaz em calorosos debates durante as divulgações - outro comportamento típico de um diretor. Decerto, Huillet foi muitas vezes esquecida ou menosprezada e Crônica de Anna Magdalena Bach, com sua forma vicária, em duplicata, enseja apanhar imprescindivelmente o cinema huillet-straubiano pelo viés feminista, sem impor tal discussão de modo extrínseco.

Ao ser indagada sobre a questão de gênero, Huillet repudia a fabulação audiovisual do protagonismo feminino de acordo com a lógica estandardizada da "fábrica de sonhos"24: "Eu não acredito que alguém possa substituir uma opressão por outra, e também não acredito que alguém consiga combater um sistema com outro, porque então uma coisa se torna simplesmente muito rígida” ${ }^{25}$. Similar é seu retruque quanto ao incômodo com o não reconhecimento ocasional de sua autoria: "O que nos interessa são os produtos e não os nomes" ${ }^{\text {26 }}$. Deduz-se, portanto, que nada adianta alçar as mulheres ao centro do imaginário se se preserva a violência do padrão, pois assim também se esquiva do ato fílmico como testemunho das contradições, falseando a história ao se forjar uma resolução ilusória para a subserviência feminina, o que amortece transformações efetivas. Ante tal rigidez, ainda, "eu espero", diz Huillet, "que se possa sentir a fragrância das coisas" ${ }^{27}$. Ora, não seria esse um clamor materialista-histórico por uma radicalização da sensibilidade, o que requer outros modos de produção do real?

Dalila Camargo Martins é doutoranda no Programa de Pós-Graduação em Meios e Processos Audiovisuais da Escola de Comunicação e Artes [USP], na área de História, Teoria e Crítica. Tem experiência em cinema e artes visuais, tendo atuado como crítica, curadora, professora e expositora.
182

Dalila Camargo Martins

Crônica de Anna Magdalena

Bach: amor, trabalho e morte no cinema de Danièle Huillet e Jean-Marie Straub.

24. HEBERLE, Helge; STERN, Monika. Das Feuer im Innern des Berges: Gespräch mit Danièle Huillet. Frauen und Film, Berlin, n. 32, p. 12, jun. 1982. Disponível em: <https:// goo.gl/KdrNv7>. Acesso em: 22. nov. 2017. Tradução minha.

25. Ibidem, p. 11.

26. Ibidem, p. 5 .

27. Ibidem, p. 12.

Artigo recebido em 17 de outubro de 2017 e aceito em 7 de novembro de 2017. 